\title{
Successful treatment of refractory systemic lupus erythematosus using proteasome inhibitor bortezomib followed by belimumab: description of two cases
}

Christopher Sjöwall, Maria Hjorth and Per Eriksson

The self-archived postprint version of this journal article is available at Linköping University Institutional Repository (DiVA):

http:// urn.kb.se/ resolve?urn=urn:nbn:se:liu:diva-141701

N.B.: When citing this work, cite the original publication.

Sjöwall, C., Hjorth, M., Eriksson, P., (2017), Successful treatment of refractory systemic lupus erythematosus using proteasome inhibitor bortezomib followed by belimumab: description of two cases, Lupus, 26(12), 1333-1338. https:// doi.org/ 10.1177/ 0961203317691371

Original publication available at:

https:// doi.org/ 10.1177/ 0961203317691371

Copyright: SAGE Publications (UK and US)

http:// www.uk.sagepub.com/home.nav 
TITLE PAGE

Type of manuscript: Case Report

Title: Successful treatment of refractory systemic lupus erythematosus using proteasome inhibitor bortezomib followed by belimumab: Description of two cases

Authors: Christopher Sjöwall ${ }^{1 *}$, Maria Hjorth², Per Eriksson ${ }^{1}$

Affiliations:

1) Rheumatology/AIR, and

2) Clinical Immunology \& Transfusion Medicine, Department of Clinical and Experimental Medicine, Linköping University, SE-581 85, Linköping, Sweden

* Corresponding author:

Rheumatology Unit, University Hospital, SE-581 85 Linköping, Sweden

E-mail address: christopher.sjowall@liu.se

Telephone: +46101032416 


\section{Abstract}

Although the putative therapeutic options for patients with systemic lupus erythematosus (SLE) are steadily increasing, refractory disease is indeed a major challenge to many clinicians and patients. The proteasome inhibitor bortezomib - approved for the treatment of multiple myeloma since the beginning of this century - was recently reported successful in twelve cases of refractory SLE by German colleagues. Herein, we describe two Swedish SLE cases with refractory renal and pulmonary manifestations that were rescued by bortezomib as induction of remission followed by monthly doses of belimumab. The patients were carefully monitored with regard to disease activity and renal function. Anti-dsDNA and anti-C1q antibodies, complement proteins and lymphocyte subsets were analysed in consecutive samples. In December 2016, the patients have been in clinical remission post bortezomib administration for a period of 28 and 22 months, respectively. Potential benefits of using belimumab as maintenance therapy to prevent regeneration of autoreactive B cell clones are discussed. 


\section{Introduction}

During the last decades, the management of renal involvement of systemic lupus erythematosus (SLE) has seen substantial progress. The current trend is to use lower doses of corticosteroids in combination with the Euro-Lupus regimen of cyclophosphamide (CYC) or mycophenolate mofetil (MMF) as induction therapy of nephritis $[1,2]$. However, many clinicians and patients still have experience of refractory disease. In addition, the most severe cases with active renal and/or central nervous system disease are consistently excluded from clinical trials evaluating new pharmaceuticals. Thus, there is still an urgent need for novel pharmacological interventions in severely ill patients.

The commonly used immunosuppressants in combination with corticosteroids primarily exert their therapeutic effects on B cells, plasmablasts and short-lived plasma cells $[3,4]$. To achieve effects beyond this, i.e. on the long-lived plasma cells, the only available alternatives are autologous stem cell transplantation, atacicept (blocking both BAFF and APRIL) and proteasome inhibition [4-6]. This was the rationale for evaluating bortezomib, a proteasome inhibitor approved for the treatment of multiple myeloma, in SLE cases resistant to conventional therapy. Professor Voll and colleagues recently reported bortezomib to have biological effects on the type-I interferons as well as on longlived plasma cells in such patients [7]. To our knowledge, however, the observations have so far not been confirmed by others.

We report two Swedish cases with refractory renal and pulmonary manifestations that were rescued by bortezomib as induction of remission followed by belimumab. Potential benefits of using belimumab as maintenance therapy are discussed. Oral and written informed consent was obtained from both patients. 


\section{Case descriptions}

Case-1

This non-smoking woman with Hispanic origin, born in 1955, without family history of rheumatic diseases was classified as SLE in 1997 at our unit. The diagnosis was based on skin, joint and haematological (lymphocytopenia) involvement in combination with an autoantibody profile including strongly positive speckled antinuclear antibody (ANA) staining pattern, anti-Smith, antismall nuclear ribonucleoprotein, anti-double-stranded DNA (dsDNA) detected by Crithidia luciliae test (CLIFT), and a positive Coomb's test (in the absence of haemolytic anaemia). Antiphospholipid and anti-C1q antibodies have constantly been negative. She had completed three pregnancies without complications and one early miscarriage (in $8^{\text {th }}$ week). During the first years of SLE, her symptoms were managed by low-dose prednisolone. Chloroquine was tested but terminated due to unclear effect. Hydroxychloroquine (HQ) gave itching as side-effect, and was rapidly discontinued. Four years after disease onset, the patient was diagnosed with steroid-induced diabetes mellitus.

In October 2007, she developed severe fatigue with proteinuria and cellular casts. Renal biopsy revealed mesangioproliferative lupus nephritis with both subendothelial and subepithelial electrondense deposits (WHO class III+V). Treatment with corticosteroids and MMF was initiated. Due to subjective side-effects, MMF was replaced by azathioprine (AZA) already after two weeks. AZA was discontinued on the patient's own request in February 2010, where after the only remaining immunosuppressant was a daily dose of $10 \mathrm{mg}$ prednisolone.

In December 2012, the patient presented with skin rash and polyarthritis. Methotrexate (MTX) was added, but the corticosteroids could not be tapered below 10 mg daily. In June 2013, she had a new onset of haematuria, proteinuria and cellular casts. Due to low patient compliance, it was decided to 
give rituximab $1000 \mathrm{mg}$ twice, administered two weeks apart. MTX was used as maintenance. Five months later the patient suffered from an osteoporotic fracture of her left leg. Due to questionable renal response of rituximab, a renal biopsy was performed in January 2014, which showed mesangioproliferative active lupus nephritis ISN/RPS class IV-S (A/C) with full-house pattern, necrotic lesions in the mesangium and crescents found in 2/10 glomeruli whereof 1 was destroyed. CYC 500 mg every second week according to the Euro-Lupus regimen was initiated in combination with higher doses of corticosteroids [2].

Four months later, when the patient still had active urinary sediment and increased proteinuria, she complained of cough and fever. A chest X-ray indicated pneumonia, but the response to broadspectrum antibiotics was modest. The respiratory function was rapidly worsened. Computed tomography (CT) was performed; diffuse alveolar bleeding was suggested and confirmed by bronchoscopy. Hemosiderin-laden macrophages in bronchoalveolar lavage fluid were identified.

Plasmapheresis was initiated and the patient received in total 14 courses during June-July 2014 . She became anuric and was treated with haemodialysis and assisted ventilation at the intensive care unit. Assessment of lymphocyte subsets (absolute counts and percentage) was performed with flow cytometry at the accredited laboratory of Clinical Immunology and Transfusion Medicine at Linköping University Hospital (Table 1). In mid-July, bortezomib in combination with dexamethasone was initiated and given in one cycle according to the scheme suggested by Alexander et al [7]. The administration of bortezomib was followed by infections (systemic Candida albicans and cytomegalovirus) which prevented a second bortezomib cycle, but the renal function as well as the serological activity improved rapidly (Figure 1A). The occurrence of the infections coincided with a significant reduction of IgG in plasma (Figure 1D). 
In late August 2014, belimumab was introduced as maintenance in an attempt to decrease new plasma cells. A daily background of HQ $200 \mathrm{mg}$ and prednisolone $7.5 \mathrm{mg}$ was also given. Belimumab $600 \mathrm{mg}$ intravenously has successfully been repeated monthly during more than two years without recurrence of anti-dsDNA antibodies, complement consumption, active urinary sediment or signs of extra-renal disease activity, and Coomb's test became negative post bortezomib treatment. Of note, however, during the first year of belimumab the patient suffered from one pyelonephritis and one upper respiratory tract infection which both required treatment with oral antibiotics. At last followup (in December 2016), the patient was still on a low dose of prednisolone, $7.5 \mathrm{mg}$ daily.

\section{Case-2}

This Caucasian woman, born in 1975, with affirmed photosensitivity since childhood and three pregnancies without complications, was admitted to our rheumatology unit in the fall of 2009 due to polyarthritis. During 1997-98, she suffered from an episode of Guillain-Barré syndrome with symmetric muscle weakness and acute inflammatory demyelinating polyneuropathy; effective treatment with intravenous immunoglobulins made her completely recovered. Her grandmother also had arthritis and had been judged as suspected primary Sjögren's syndrome. At the patient's first visit, the consultant rheumatologist found symmetrical synovitis of the proximal interphalangeal joints. The autoantibody profile revealed a positive ANA with speckled staining pattern and anti-SSA (both Ro52/TRIM21 and Ro60). Low-dose corticosteroids were initiated on the suspicion of lupus arthritis.

Three months later, the patient was affected by a pleuritis confirmed on X-ray. Treatment with higher doses of corticosteroids in combination with $\mathrm{HQ}$ and AZA was successful. AZA was 
discontinued after six months due to subjective side-effects. In 2011, the patient occasionally demonstrated skin rash and complained on pronounced continuous tiredness and musculoskeletal pain. Low-dose dehydroepiandrosterone was initiated during one year, in hope of improving the fatigue, but the effect was modest. In early 2013, the patient experienced more arthralgia and MTX was initiated. ANA and anti-SSA were still positive, now with the addition of anti-dsDNA in a titre of 1:160 detected by CLIFT but Coomb's test was negative. Six months later, a skin lesion showed discoid lupus on biopsy. MTX was discontinued due to lack of efficacy and MMF 2000 mg daily was started.

In April 2014, albumin on urine dipstick, haematuria, a moderate amount of urinary casts was detected in combination with slightly elevated plasma creatinine. Renal biopsy demonstrated diffuse proliferative lupus nephritis ISN/RPS class IV-S (A/C) with crescents in 9/16 glomeruli and segmental necrosis in 4/16, but only limited fibrosis. Deposits of immunoglobulins and complement components were significant. Corticosteroids were administered intravenously in combination with an initial dose of $800 \mathrm{mg} \mathrm{CYC} \mathrm{followed} \mathrm{by} \mathrm{the} \mathrm{Euro-Lupus} \mathrm{regimen,} \mathrm{and} \mathrm{the} \mathrm{dose} \mathrm{of} \mathrm{HQ} \mathrm{was} \mathrm{increased}$ to $400 \mathrm{mg}$ daily [2]. Three months later, MMF was re-started. However, creatinine did not normalize, proteinuria remained substantial, and urine dipstick still revealed persistent haematuria. Rituximab 1000 mg twice administered two weeks apart was given in October 2014 and the corticosteroids were eventually tapered. A renal re-biopsy in February 2015 (ten months after the previous biopsy) confirmed a histopathological picture compatible with active diffuse lupus nephritis classified as ISN/RPS class IV-S (A/C), whereas the immune deposits were now sparse. Crescents were found in 14/22 glomeruli and 3/22 were destroyed.

During March-April 2015, bortezomib in combination with dexamethasone was administered in two cycles according to the scheme suggested by Alexander et al [7]. After the second cycle, belimumab 
was introduced as maintenance on a daily background of MMF 2000 mg, HQ 200 mg and prednisolone $5 \mathrm{mg}$. Belimumab $800 \mathrm{mg}$ intravenously has been repeated monthly. Apart from acute appendicitis (in July 2016), the treatment has been free of side-effects. Of note, since the bortezomib cycles the patient's morphine demanding musculoskeletal pain has almost entirely disappeared. In August 2016, a third renal biopsy was performed (18 months after the previous biopsy) which revealed inactive nephritis as cellular crescents had been replaced by sclerotic crescents in $16 / 45$ glomeruli. No fresh crescents were found. $30 \%$ of the cortex was fibrotic. During the last year, raised disease activity has not been observed but a decreasing anti-dsDNA antibody titre is still present (Figure 2B and 2E). At last follow-up (in December 2016), the patient had been completely free from corticosteroids for four months.

\section{Discussion}

The interest for drugs used in haematology is not new among rheumatologists. Rituximab was an important treatment option for lymphomas already long before its introduction in rheumatology, but nowadays, rituximab is a biologic of great importance, e.g. in rheumatoid arthritis and ANCAassociated vasculitis [8]. Whether rheumatologists will adopt bortezomib as a new family member is still an open question, but it is clear that some patients with refractory SLE have benefited from this drug.

Mechanisms of action of the 265 proteasome inhibitor bortezomib may include inhibition of nuclear factor-kB (NF-kB) and modulation of the tumour microenvironment, including cytokine expression and stromal cell interactions $[3,6]$. In addition, it contributes to the accumulation of misfolded proteins within the endoplasmic reticulum and thereby activates the terminal unfolded protein 
response leading to apoptosis [9]. The long-lived plasma cells are magnificent antibody producers, and are thus highly sensitive to proteasome inhibition [6].

The cases described herein with renal and pulmonary involvement resistant to conventional therapies are rare. The first case had a life-threating disease preceded by a long history of serological activity and bad compliance. Two years after the administration of bortezomib, the anti-dsDNA antibody tests (two different techniques) are still negative and complement proteins are normal (Figure 1). The second case was complicated since the renal histopathology repeatedly showed serious lesions with crescents and significant immune deposits despite normal complements and very limited urinary findings. Eighteen months after the administration of bortezomib the urine albumin/creatinine ratio and albumin in plasma have normalized, and anti-C1q levels decreased significantly (Figure 2). In addition, the latest renal biopsy showed predominantly chronic lesions with very limited immunoglobulin deposits.

In both patients, assessment of lymphocyte subsets revealed a normalization of NK cells, helper and cytotoxic T cells during the treatment cycles whereas B cells and plasmablasts were already low after treatment with rituximab, and remained subnormal during and after bortezomib (Table 1). However, it is likely that clones of long-lived plasma cells in the bone marrow were of significant pathogenic importance. Since mature plasma cells lack CD20, they escaped rituximab treatment but were efficiently removed by bortezomib. Subsequently, we aimed to neutralize BAFF by using belimumab as maintenance therapy in order to prevent regeneration of autoreactive clones. The effect of bortezomib is short-lived and animal data indicate that continuous B cell inhibition is needed to achieve sustained plasma cell depletion and renal amelioration [10]. Belimumab is a well-tolerated drug and compliance can easily be monitored, but whether belimumab alone is sufficient to prevent autoreactive plasmablasts from re-developing from their progenitor memory B cells remains 
uncertain [10-12]. In our hands, however, both patients have been in clinical remission since the introduction of belimumab.

\section{Conclusion}

We report two SLE cases with severe disease who did not respond to conventional therapies. One or two cycles of bortezomib in combination with dexamethasone as induction therapy gave substantial effect on both clinical and serological parameters, and maintenance with belimumab has so far been well tolerated. Our findings are in line with previous observations $[6,7,10]$. Thus, proteasome inhibition constitutes a promising new alternative for patients with refractory lupus. Further evaluation in clinical trials is warranted.

\section{Acknowledgements}

Dr. Jonas Wetterö is acknowledged for comments on the manuscript. This research received no specific grant from any funding agency in the public, commercial, or not-for-profit sectors.

\section{Declaration of Conflicting Interests}

The authors declared no potential conflicts of interest with respect to the research, authorship, and/or publication of this article. 


\section{References:}

1. Lightstone L. Minimising steroids in lupus nephritis - will B cell depletion pave the way? Lupus 2013; 22: 390-99

2. Houssiau FA, Vasconcelos C, D'Cruz D, Sebastiani GD, Garrido Ed Ede R, Danieli MG, Abramovicz D, Blockmans D, Mathieu A, Direskeneli H, Galeazzi M, Gül A, Levy Y, Petera P, Popovic R, Petrovic R, Sinico RA, Cattaneo R, Font J, Depresseux G, Cosyns JP, Cervera R. Immunosuppressive therapy in lupus nephritis: the Euro-Lupus Nephritis Trial, a randomized trial of low-dose versus high-dose intravenous cyclophosphamide. Arthritis Rheum 2002; 46: 2121-31

3. Alexander T, Thiel A, Rosen O, Massenkeil G, Sattler A, Kohler S, Mei H, Radtke H, GromnicaIhle E, Burmester GR, Arnold R, Radbruch A, Hiepe F. Depletion of autoreactive immunologic memory followed by autologous hematopoietic stem cell transplantation in patients with refractory SLE induces long-term remission through de novo generation of a juvenile and tolerant immune system. Blood 2009; 113: 214-23

4. Hoyer BF, Moser K, Hauser AE, Peddinghaus A, Voigt C, Eilat D, Radbruch A, Hiepe F, Manz RA. Short-lived plasmablasts and long-lived plasma cells contribute to chronic humoral autoimmunity in NZB/W mice. J Exp Med 2004; 199: 1577-84

5. Benson MJ, Dillon SR, Castigli E, Geha RS, Xu S, Lam KP, Noelle RJ. Cutting edge: the dependence of plasma cells and independence of memory B cells on BAFF and APRIL. J Immunol 2008; 180: 3655-59

6. Neubert K, Meister S, Moser K, Weisel F, Maseda D, Amann K, Wiethe C, Winkler TH, Kalden JR, Manz RA, Voll RE. The proteasome inhibitor bortezomib depletes plasma cells and protects mice with lupus-like disease from nephritis. Nat Med 2008; 14: 748-55

7. Alexander T, Sarfert R, Klotsche J, Kühl AA, Rubbert-Roth A, Lorenz HM, Rech J, Hoyer BF, Cheng Q, Waka A, Taddeo A, Wiesener M, Schett G, Burmester GR, Radbruch A, Hiepe F, Voll RE. The proteasome inhibitior bortezomib depletes plasma cells and ameliorates clinical manifestations of refractory systemic lupus erythematosus. Ann Rheum Dis 2015; 74: 147478

8. Rath E, Zwerina J, Oppl B, Nell-Duxneuner V. Efficacy and safety of rituximab in rheumatic diseases. Wien Med Wochenschr 2015; 165 :28-35

9. Obeng EA, Carlson LM, Gutman DM, Harrington WJ Jr, Lee KP, Boise LH. Proteasome inhibitors induce a terminal unfolded protein response in multiple myeloma cells. Blood 2006; 107: 4907-16

10. Khodadadi L, Cheng Q, Alexander T, Sercan-Alp Ö, Klotsche J, Radbruch A, Hiepe F, Hoyer BF, Taddeo A. Bortezomib plus continuous $B$ cell depletion results in sustained plasma cell depletion and amelioration of lupus nephritis in NZB/W F1 mice. PLoS One 2015; 10: e0135081

11. Parodis I, Axelsson M, Gunnarsson I. Belimumab for systemic lupus erythematosus: a practice-based view. Lupus 2013; 22: 372-80

12. Taddeo A, Khodadadi L, Voigt C, Mumtaz IM, Cheng Q, Moser K, Alexander T, Manz RA, Radbruch A, Hiepe F, Hoyer BF. Long-lived plasma cells are early and constantly generated in New Zealand Black/New Zealand White F1 mice and their therapeutic depletion requires a combined targeting of autoreactive plasma cells and their precursors. Arthritis Res Ther 2015; 17: 39 


\section{FIGURE LEGENDS}

Figure 1: Laboratory data from Case-1 presented with (A) urine albumin/creatinine ratio (ref. $<3.0$ $\mathrm{g} / \mathrm{mol}$ ), plasma creatinine (ref. $<90 \mu \mathrm{mol} / \mathrm{L}$ ) and SLE disease activity index-2K; (B) antibodies to double-stranded (ds) DNA (CLIFT) and plasma albumin (ref. 36-45 g/L); (C) complement proteins C3 (ref. 0.70-1.3 g/L) and C4 (ref. 0.13-0.32 g/L); (D) immunoglobulin G (ref. 6.7-15 g/L), A (ref. 0.88-4.5 g/L) and M (ref. 0.27-2.1 g/L); and (E) autoantibodies detected by 'Addressable Laser Bead Immunoassay': anti-dsDNA (ref. $<80 \mathrm{IU} / \mathrm{mL}$ ), anti-ribosomal P, anti-U1RNP and anti-Sm (ref. $<40$ $\mathrm{IU} / \mathrm{mL}$ ). Months indicate time since diagnosis of SLE. The dotted line illustrates time-point of bortezomib administration.

Figure 2: Laboratory data from Case-2 presented with (A) urine albumin/creatinine ratio (ref. $<3.0$ $\mathrm{g} / \mathrm{mol}$ ), plasma creatinine (ref. $<90 \mu \mathrm{mol} / \mathrm{L}$ ) and SLE disease activity index-2K; (B) antibodies to double-stranded (ds) DNA (CLIFT), antibodies to C1q and plasma albumin (ref. 36-45 g/L); (C) complement proteins C3 (ref. 0.70-1.3 g/L) and C4 (ref. 0.13-0.32 g/L); (D) immunoglobulin G (ref. 6.7-15 g/L), A (ref. 0.88-4.5 g/L) and M (ref. 0.27-2.1 g/L); and (E) autoantibodies detected by 'Addressable Laser Bead Immunoassay': anti-dsDNA (ref. $<80 \mathrm{IU} / \mathrm{mL}$ ), anti-Ro52/TRIM21 (ref. $<40$ $\mathrm{IU} / \mathrm{mL}$ ) and anti-Ro60 (ref. $<50 \mathrm{IU} / \mathrm{mL}$ ). Months indicate time since diagnosis of SLE. The dotted lines illustrate time-points of bortezomib administration.

\section{Table 1:}

Lymphocyte subsets performed with flow cytometry (indicated by absolute counts and percentage) demonstrated for both cases. Arrows indicate time-points of bortezomib administration. 
* Not analysed with high-sensitive B cell panel. Results from regular lymphocyte subset analysis shown. 


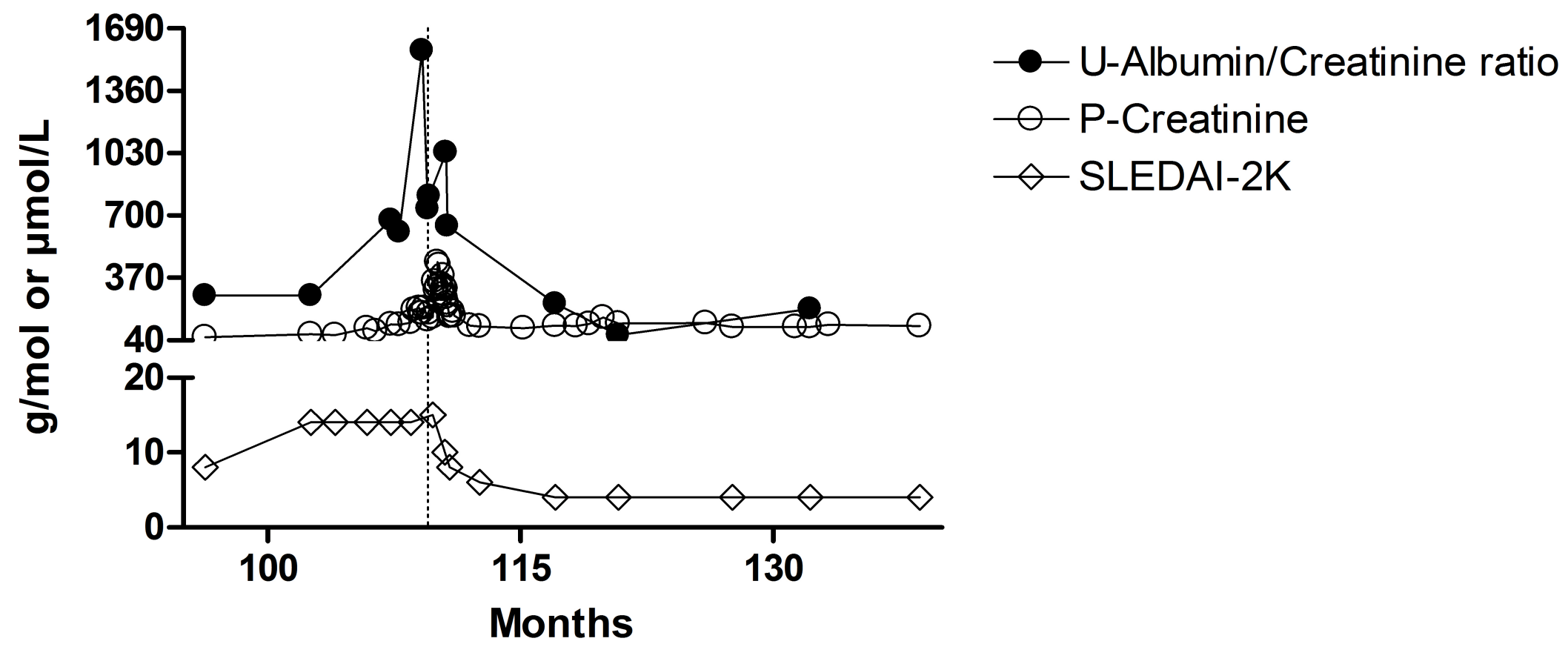




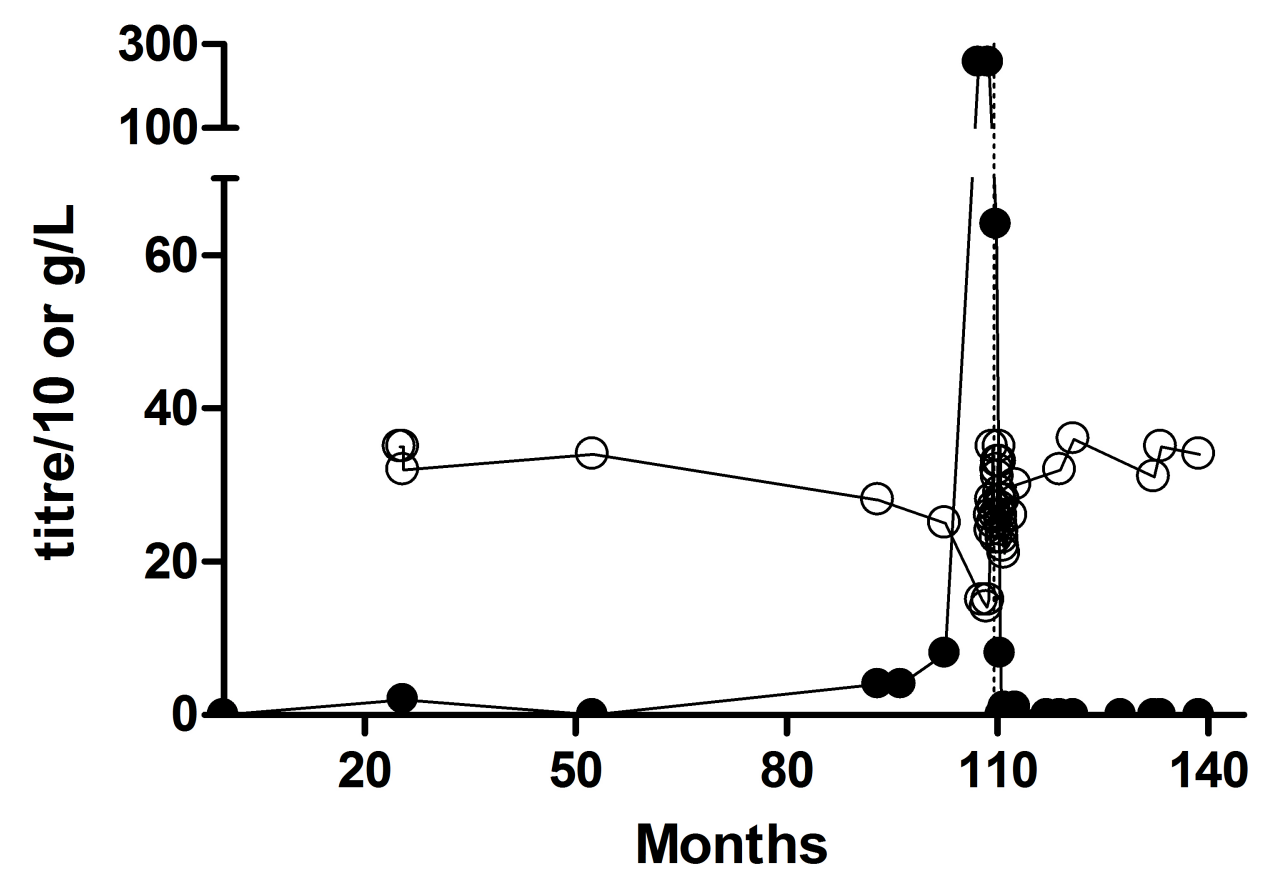

$\longrightarrow$ anti-dsDNA (CLIFT)

$\bigcirc$ P-Albumin 


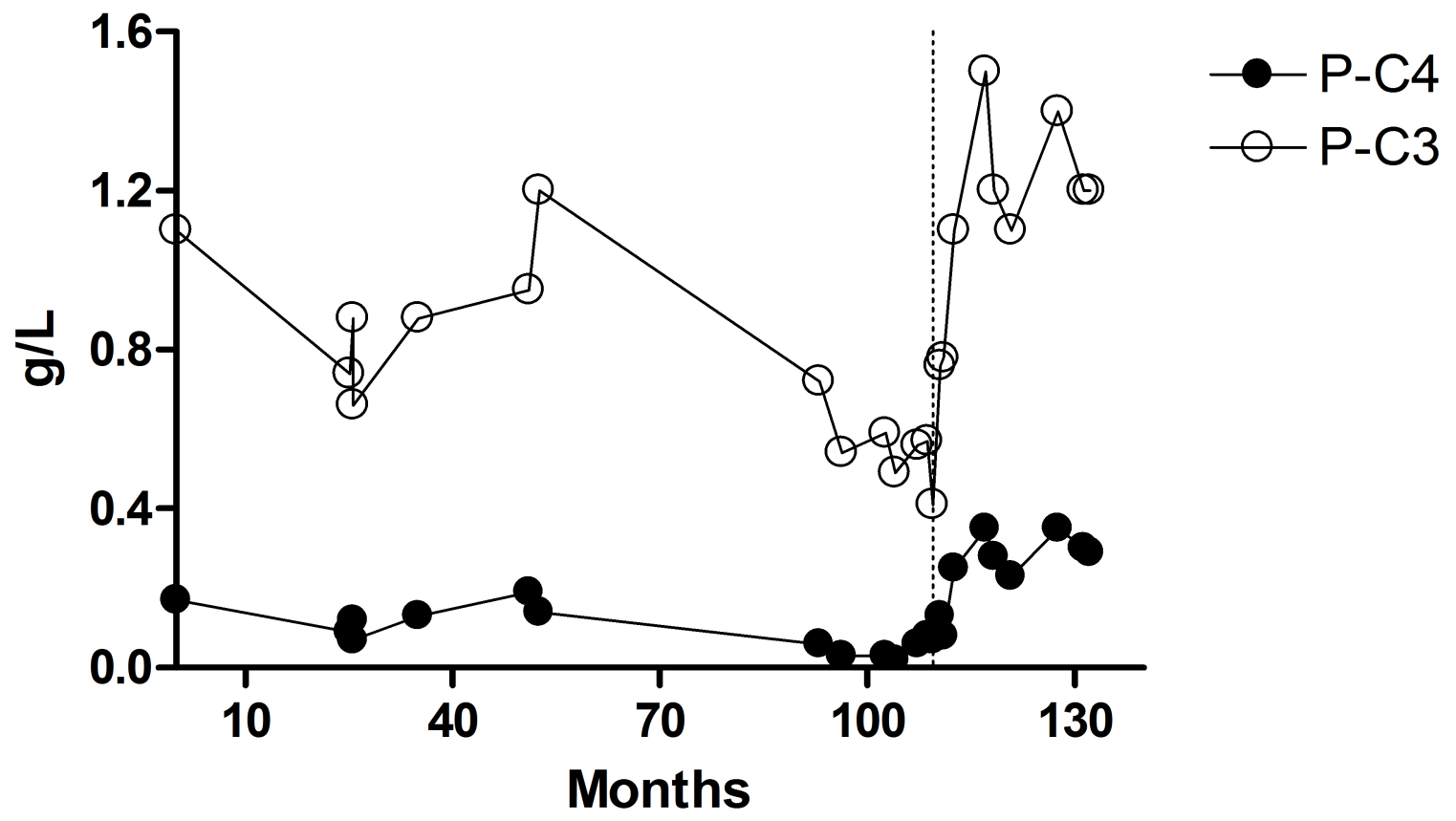




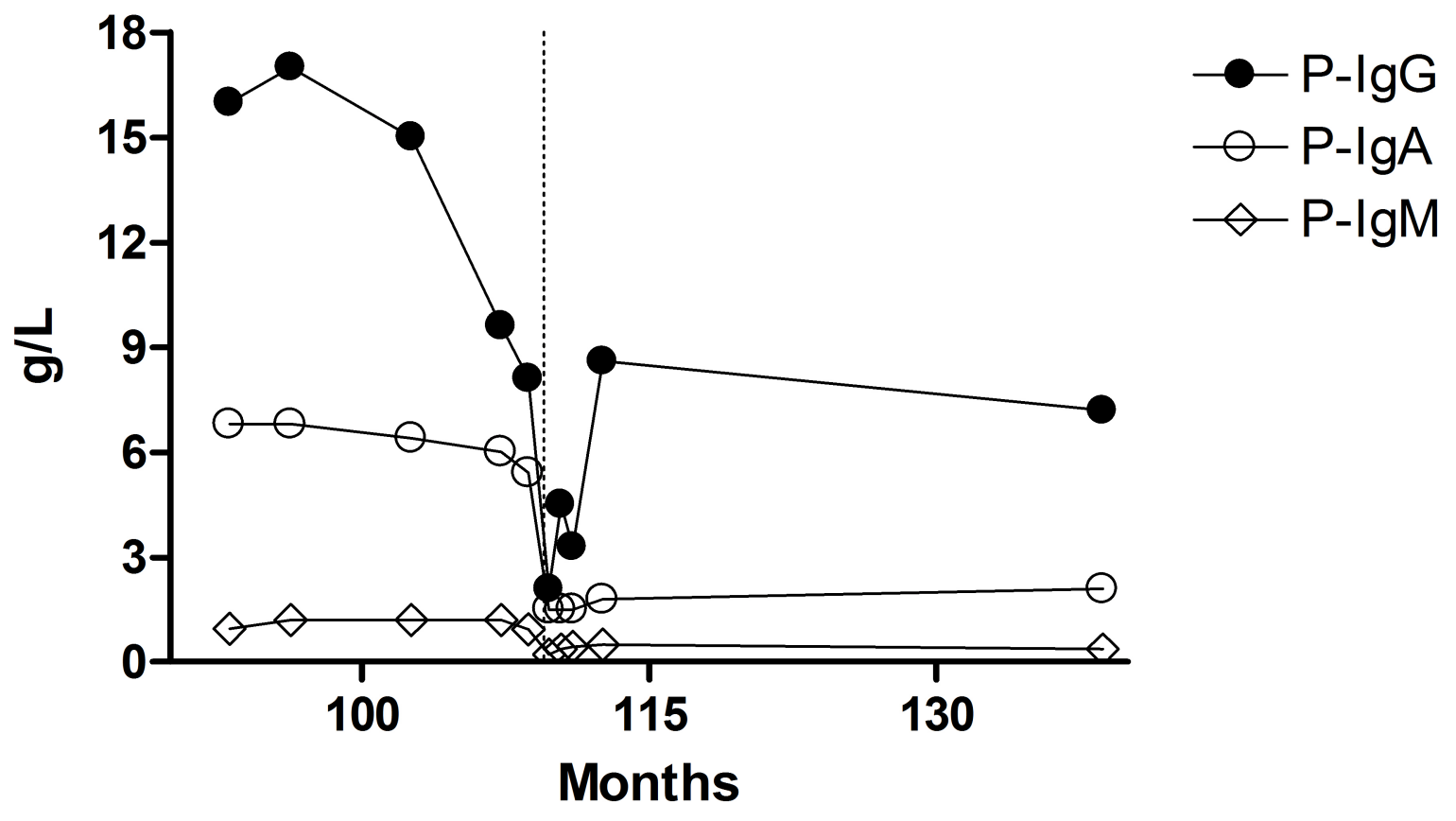




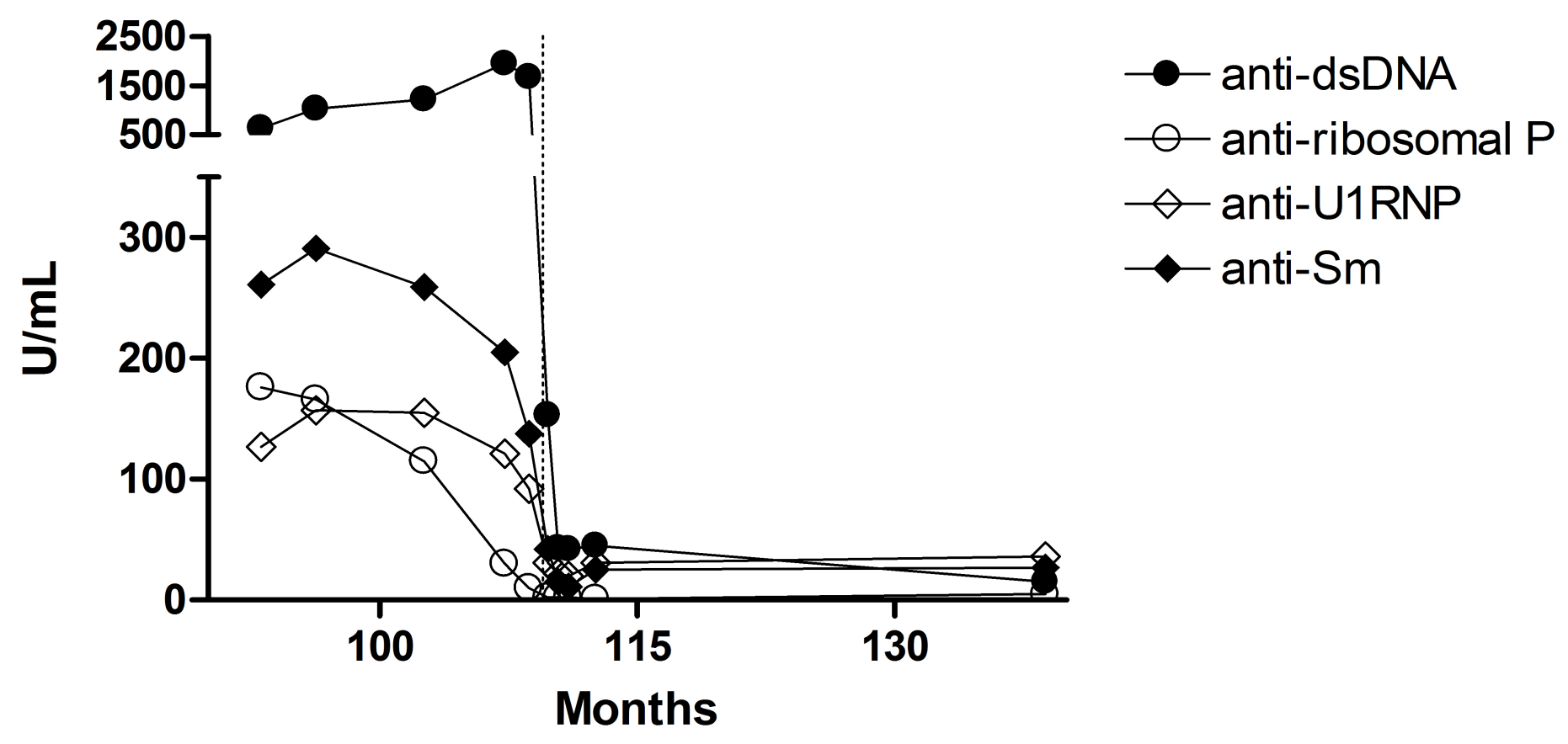




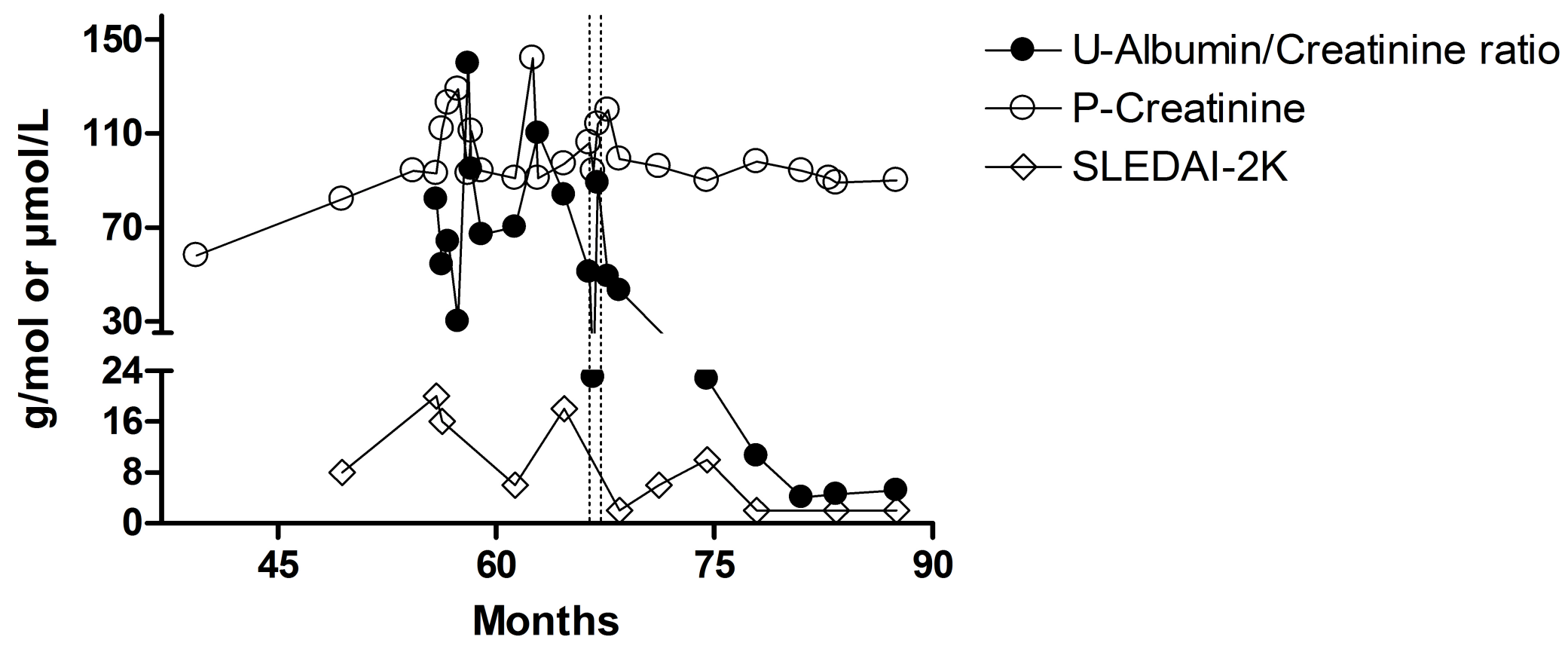




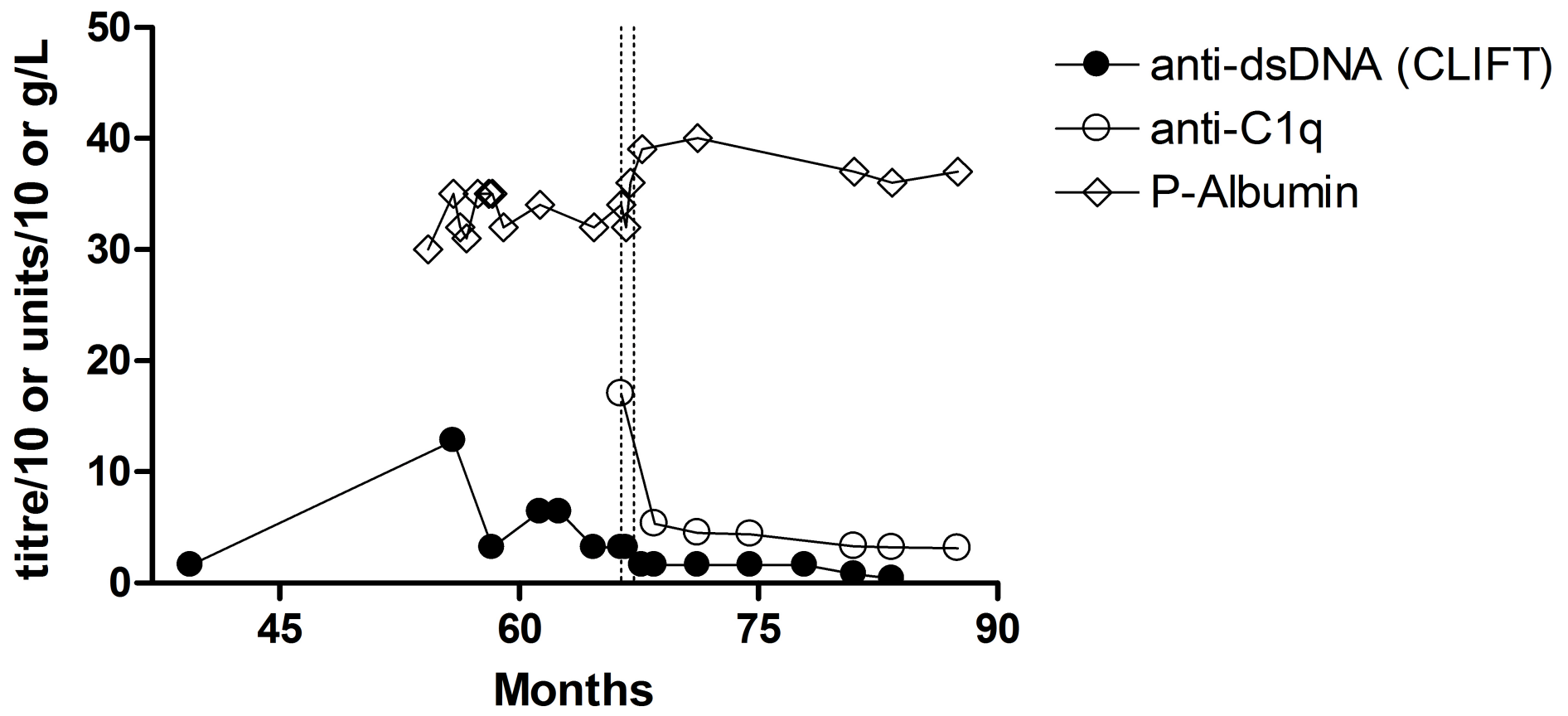




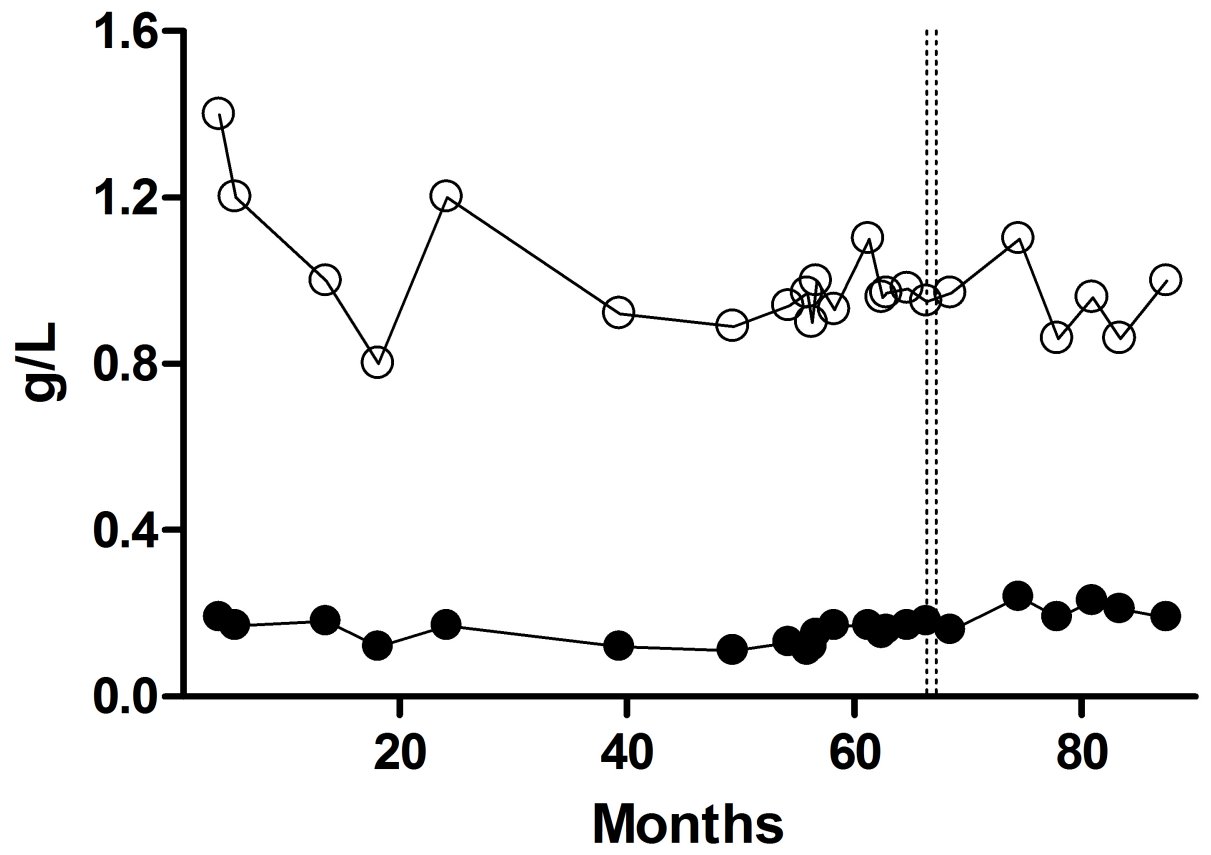




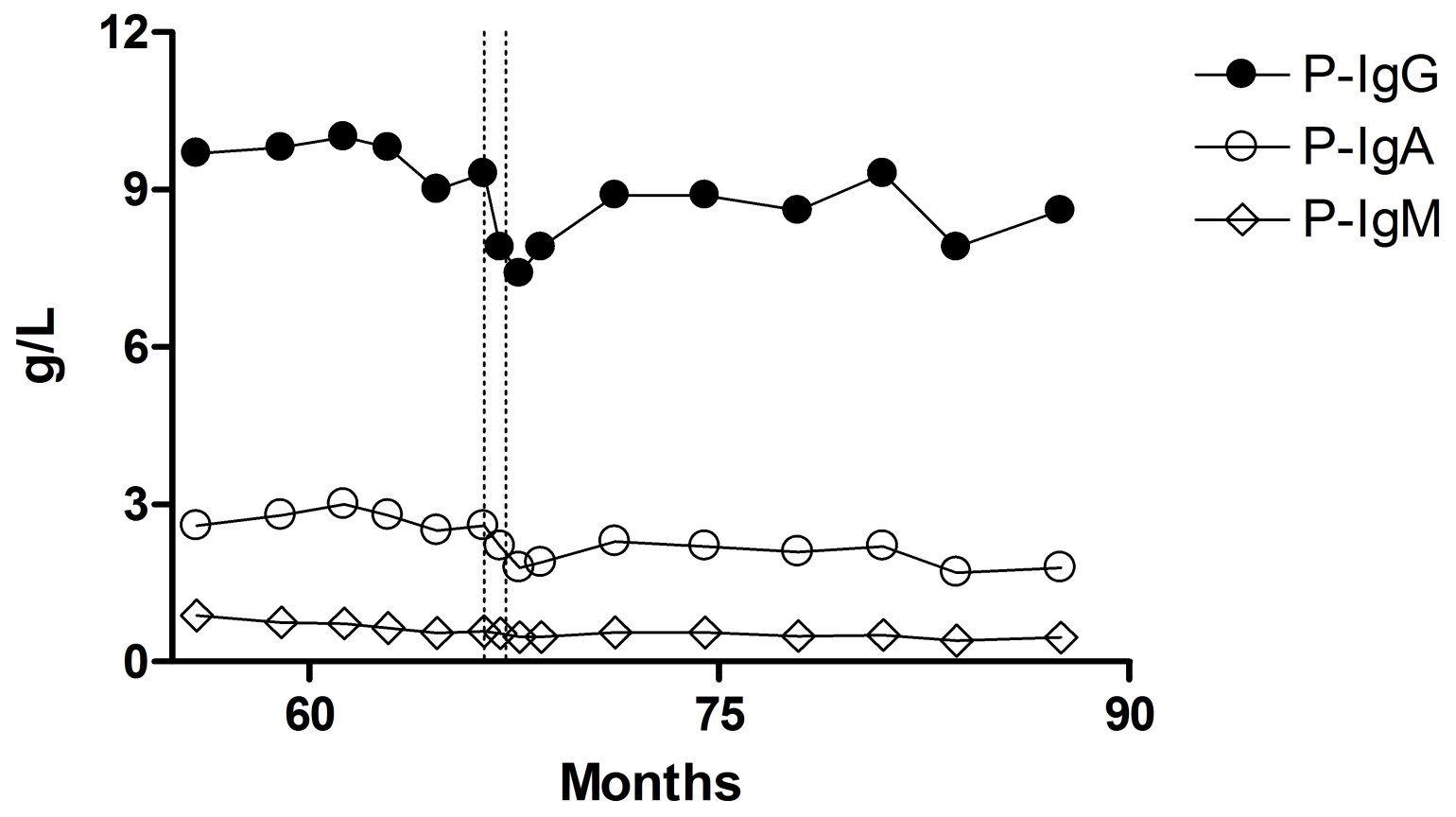




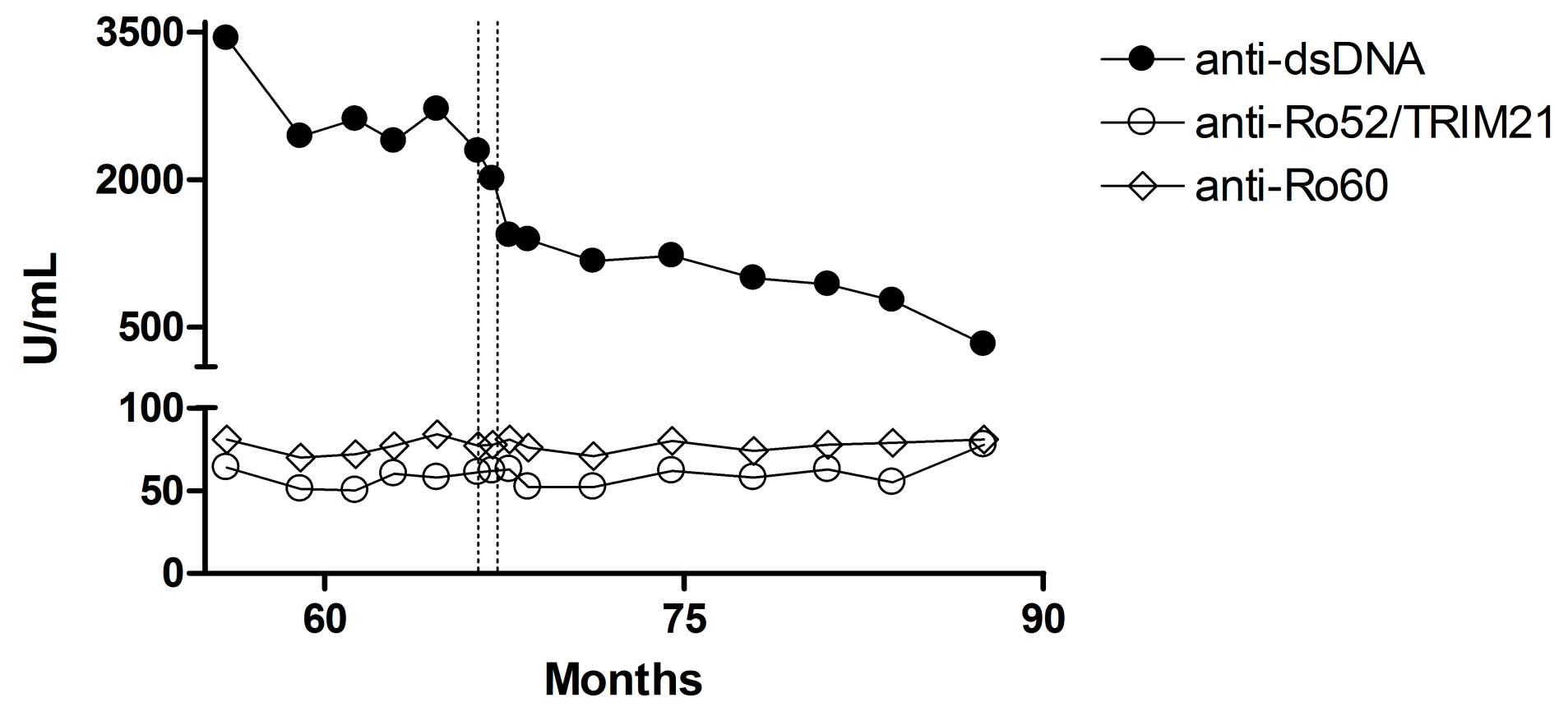

